HPV

\title{
Mexican physicians' knowledge and attitudes about the human papillomavirus and cervical cancer: a national survey
}

\author{
T Aldrich, D Becker, S G García, D Lara
}

Sex Transm Infect 2005;81:135-141. doi: 10.1136/sti.2003.008557

See end of article for authors' affiliations

.....................

Correspondence to: S G García, Population Council, Panzacola 62, Interior 102, Population Council, Col Villa Coyoacán, Mexico DF 04000, Mexico; sgarcía@ popcouncil.org.mx

Accepted for publication 28 May 2004

\begin{abstract}
Objective: To assess Mexican physicians' knowledge about the human papillomavirus (HPV) and cervical cancer and their opinions and practices related to screening, managing, and counselling women on these topics.

Methodology: In August 2002 we surveyed 1206 general practitioners (GPs) and obstetriciansgynaecologists (Ob-Gyns) working in a nationally representative sample of public and private facilities in urban Mexico. Eligible physicians completed a self administered questionnaire. We conducted a weighted analysis and used $\chi^{2}$ tests to compare GPs and Ob-Gyns on outcome variables.

Results: $76 \%$ of recruited physicians responded to the survey. $43 \%$ of Ob-Gyns had performed a hysterectomy in the last year to treat a case of CIN I or II. With respect to HPV, while $80 \%$ of respondents identified the virus as the principal cause of cervical cancer, many lacked detailed knowledge about this association. Ob-Gyns were more likely than GPs to have heard about specific oncogenic strains of HPV $(p<0.001)$. Nearly all respondents thought that women should be informed that HPV causes cervical cancer; nevertheless, physicians believed that positioning cervical cancer as a sexually transmitted infection (STI) could cause problems in partner relationships (60\%), confusion (40\%), and unnecessary anxiety among women (32\%).

Conclusions: Mexican physicians support patient education on the HPV-cervical cancer link. However, findings suggest the need to present clear messages to women (emphasising, for example, that only certain types of HPV are oncogenic), to consider the conflicts such information might create for couples, and to further educate physicians about this topic and about overall cervical cancer screening and treatment protocols.
\end{abstract}

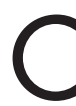
ervical cancer is the second most common cancer in women, with an estimated 500000 new cases and 231000 deaths annually worldwide. ${ }^{2}$ Latin America has among the highest incidence rates in the world, and unlike the United States and Canada, most of the region has seen little improvement in the past 30 years. In Mexico, cervical cancer remains a leading cause of death among women of reproductive age with a stable mortality rate of around 17/100 000 despite a national screening programme since $1974 .^{3}$ Several factors contribute to cervical cancer rates in Mexico, including low coverage of Papanicolaou (Pap) smears especially among high risk women such as those in rural areas with limited contact with the health system, poor quality of cytology services, and lack of follow up for women with abnormal Pap results. One study found that only $64 \%$ of women aged 15-49 in Mexico City and 30\% in the state of Oaxaca had ever had a Pap test in their lifetime. ${ }^{4}$

Since the mid-1990s, clinical evidence has established the human papillomavirus (HPV) as a necessary cause of cervical cancer. ${ }^{5}$ Knowledge of this association has spurred research on HPV based strategies for cervical cancer prevention, including primary prevention of HPV, HPV vaccines, and the use of HPV testing for follow up of women with abnormal Pap results and post-treatment for severe lesions or microinvasive cancer. These clinical advances imply the need for appropriate education among both providers and the public. Physicians must remain up to date with research on HPV and cervical cancer diagnostic and treatment technologies. Clear and appropriate information must also be relayed to women in a way that encourages healthy sexual practices and healthcare seeking behaviour. While the United States has launched large scale HPV education programmes aimed at women and the general public, ${ }^{6}{ }^{7}$ information campaigns in Mexico seldom mention HPV. In fact, general knowledge about HPV is very low; in one study with 880 women between 18 and 49 years of age, $2 \%$ knew that the virus was a main risk factor for cervical cancer. ${ }^{8}$

Designing effective educational messages is not straightforward: firstly, most HPV infections regress without treatment and are undetectable within 6 months to 2 years. ${ }^{9}{ }^{10}$ Of the over $100 \mathrm{HPV}$ strains, only certain types are oncogenic. In the rare case that these strains progress to cancer, the process can take between 5 and 30 years. ${ }^{11}$ Furthermore, since HPV is transmitted through skin to skin contact, traditional barrier methods are unreliable in preventing transmission. ${ }^{12}$

Despite the role that physicians have in cervical cancer prevention and education, limited research on these topics has been conducted with Mexican providers to date. Findings from a 1998 study with 520 healthcare professionals in the state of Morelos showed poor knowledge about cervical cancer aetiology, diagnosis, and treatment, with $40 \%$ of obstetricians-gynaecologists (Ob-Gyns) unaware of the association between HPV and cervical cancer. ${ }^{13}$ Since this study, the Ministry of Health has published a programme of action on cervical cancer for 2001-6, outlining national strategies for improving screening, treatment, education, service monitoring, and research. Mexico's official cervical cancer norms were also updated in March 1998. In this context, the present

Abbreviations: CIN, cervical intraepithelial neoplasia; GPs, general practitioners; HPV, human papillomavirus; Ob-Gyns, obstetriciansgynaecologists; Pap, Papanicolaou; STI, sexually transmitted infections 
survey sought to explore, on a national level, providers' knowledge, attitudes, and practices related to cervical cancer norms in Mexico and their opinions about patient education on HPV. Given their different professional profile and training, we compared specialists (Ob-Gyns) with nonspecialists (family doctors and general practitioners (GPs)) to determine whether and how the two groups differed on these variables.

\section{METHODS AND MATERIALS \\ Sample framework}

Between July and August 2002 we surveyed a total of 1206 general practitioners, family doctors and Ob-Gyns working in a nationally representative sample of public and private health facilities in urban Mexico. Because Mexico has no national level accrediting board or registry of licensed physicians, we based our sample on the facility level. We used two Ministry of Health databases: the first, a census conducted in 2000 of public sector health facilities including those of the Secretary of Health and the Mexican Social Security Institute, and the second, a 2001 census of private facilities.

From these two databases we eliminated facilities without eligible physicians (Ob-Gyns, family doctors, or GPs). We also narrowed our sample to include only urban facilities (that is, located in municipalities with more than 2500 inhabitants), since the majority of providers in rural Mexico are still in training or are GPs with minimal professional experience. For practical reasons, we aimed to recruit four physicians per facility, thus eliminating public and private facilities with less than four full time, eligible providers.

The final sample included 1369 facilities, 845 public and 524 private, all located in urban areas of Mexico and with a total of 13900 eligible physicians, $63 \%(n=8810)$ who worked in public facilities and $37 \%(\mathrm{n}=5090)$ in private facilities. The databases registered only the total number of providers working in each facility and their specialty; names of individual physicians were not available.

Using this sampling frame, we randomly selected a total of 392 facilities stratified by three geographic regions: north, central, and south. We established quotas for each region and sampled accordingly: 131 facilities were randomly selected in the northern and central regions, respectively, and 130 in the southern region, with the aim of collecting a total of 400 questionnaires within each of the three regions (see table 1). Using a 95\% confidence interval (CI), we calculated a margin of error of $4.6 \%$ for the north, $4.8 \%$ for the central region, and $4.6 \%$ for the south. We planned to complete four interviews with GPs, family doctors or Ob-Gyns in each health facility, resulting in a potential sample size of 1586 physicians. The sample of eligible facilities was calculated anticipating a nonresponse rate among physicians of 30\% ( $n=386$ interviews). National estimates had a margin of error of plus or minus $2.73 \%$ at a $95 \%$ CI.

\section{Questionnaire and data collection}

We used a self administered, anonymous questionnaire that was part of a larger survey also assessing physicians' knowledge, attitudes, and practices regarding abortion in Mexico. The instrument included 56 questions-12 on sociodemographic variables, 28 on abortion, and 16 on cervical cancer and HPV. This paper reports results only for the cervical cancer/HPV portion of the survey. The questions were developed in collaboration with Mexico City gynaecologists, oncologists, and cervical cancer experts, and all items were piloted.

The survey team consisted of 74 interviewers and 25 field supervisors. The Population Council (PC) contracted the Mexican market research firm, Investigación de Mercado y Asesoría (IDM), to conduct fieldwork. Interviewers first met with each hospital or health centre director to explain study objectives and deliver a packet of literature on the nongovernmental organisation conducting the study (Population Council), as well as information on a nationwide toll free number for participating physicians to call with study related questions. Where the director gave consent for his staff to participate, interviewers delivered the questionnaire to four eligible providers selected conveniently. The interviewers were instructed to seek out eligible physicians in the emergency room, outpatient, and inpatient services from each facility. They returned 2 days later to collect the surveys, which participants were asked to place in a sealed envelope. As compensation, we included two scientific articles about reproductive health topics other than abortion or cervical cancer. This study complied with institutional procedures for ethical review, and all informed consent forms were reviewed and approved.

\section{Data analysis}

Data were entered using SPSS version 4.5 and analysed with SPSS version 10 . We conducted a weighted analysis since the study was carried out using quotas that were not proportional to the distribution of physicians in the sampling frame. Weights were calculated based on the distribution of doctors in the sample framework which contained 19825 physicians: $17.9 \%$ (3559) in the north, 63.1\% (12 940) in the central region, and $16.2 \%$ (3326) in the south. Physicians were distributed in the sample in the following way: $33.6 \%$ (406) in the north, 35.3\% (426) in the central region, and 31\% (374) in the south. To calculate the weights to be applied to each region, the framework distribution was divided by the actual sample: north $(17.9 \% / 33.6 \%=0.5327)$, central $(65.3 \%$ / $35.3 \%=1.8499)$, and south $(16.8 \% / 31.0 \%=0.5419)$.

We used $\chi^{2}$ tests to compare Ob-Gyns and GPs/family doctors on outcome variables. In Mexico, the services offered by GPs and family doctors are similar. The difference lies in that GPs belong to the Social Security Institute, which primarily serves government employees, while family doctors practise within the Secretary of Health. For purposes of this

Table 1 Distribution of health facilities and selected physicians in final sample. National survey of knowledge and attitudes regarding cervical cancer and HPV, Mexico 2002

\begin{tabular}{|c|c|c|c|c|}
\hline & Total & North & Central & South \\
\hline & No & No (\%) & No (\%) & No (\%) \\
\hline Total facilities & 288 & $96(33)$ & $103(36)$ & $89(31)$ \\
\hline Physicians & 1206 & 406 (34) & $426(35)$ & 374 (31) \\
\hline Public facilities & 170 & $58(34)$ & $50(29)$ & $62(36)$ \\
\hline Physicians & 694 & $243(35)$ & $185(27)$ & 266 (38) \\
\hline Private facilities & 118 & 38 (32) & $53(45)$ & $27(23)$ \\
\hline Physicians & 512 & $163(32)$ & 241 (47) & 108 (21) \\
\hline
\end{tabular}


Table 2 Mexican physicians' sociodemographic, and professional characteristics $(n=1206)^{*}$

\begin{tabular}{|c|c|c|c|c|}
\hline \multirow[b]{2}{*}{ Characteristic } & \multirow[b]{2}{*}{ Total } & \multicolumn{3}{|c|}{ Provider type } \\
\hline & & $\begin{array}{l}\text { Ob-Gyns } \\
\text { No }(\%)\end{array}$ & $\begin{array}{l}\text { GPs } \\
\text { No (\%) }\end{array}$ & $\mathrm{p}$ Value \\
\hline \multicolumn{5}{|l|}{ Region } \\
\hline North & $216(18)$ & $78(26)$ & $138(15)$ & \multirow[t]{3}{*}{0.000} \\
\hline Central & $787(65)$ & $177(60)$ & $610(67)$ & \\
\hline South & $203(17)$ & $41(14)$ & $162(18)$ & \\
\hline \multicolumn{5}{|l|}{ Age (years) } \\
\hline $22-34$ & $300(25)$ & $64(22)$ & $236(26)$ & \multirow[t]{3}{*}{0.170} \\
\hline $35-44$ & 405 (34) & 111 (38) & $294(32)$ & \\
\hline 45 and older & $500(42)$ & $120(41)$ & $380(42)$ & \\
\hline \multicolumn{5}{|l|}{ Sex } \\
\hline Male & $835(69)$ & $213(72)$ & $622(68)$ & \multirow[t]{2}{*}{0.247} \\
\hline Female & $371(31)$ & $83(28)$ & $288(32)$ & \\
\hline \multicolumn{5}{|l|}{ Civil status } \\
\hline Single & 225 (19) & $43(15)$ & $182(20)$ & \multirow[t]{2}{*}{0.039} \\
\hline $\begin{array}{l}\text { Married (includes free union, } \\
\text { divorced, widowed) }\end{array}$ & $982(81)$ & $253(86)$ & $729(80)$ & \\
\hline \multicolumn{5}{|l|}{ Bimonthly salary (Mexican pesost) } \\
\hline Up to $\$ 3500$ & $260(22)$ & $28(10)$ & $232(26)$ & \multirow[t]{4}{*}{0.000} \\
\hline$\$ 3501-\$ 9000$ & $561(48)$ & 109 (38) & $452(51)$ & \\
\hline$\$ 9001-\$ 13500$ & $215(18)$ & $79(27)$ & $136(15)$ & \\
\hline$>\$ 13500$ & $141(12)$ & $73(25)$ & $68(8)$ & \\
\hline \multicolumn{5}{|l|}{ Religion } \\
\hline Catholic & $1036(86)$ & $256(87)$ & $780(86)$ & \multirow[t]{3}{*}{0.723} \\
\hline Other & $91(8)$ & 20 (7) & $71(8)$ & \\
\hline None & $73(6)$ & $20(7)$ & $53(6)$ & \\
\hline \multicolumn{5}{|l|}{ Frequency of church assistance } \\
\hline Never or almost never & $496(42)$ & $123(42)$ & $373(41)$ & \multirow[t]{3}{*}{0.910} \\
\hline $1-2$ a month & $359(30)$ & $85(29)$ & $274(30)$ & \\
\hline 1 or more times a week & $341(29)$ & $85(29)$ & $256(28)$ & \\
\hline \multicolumn{5}{|l|}{ Medical school } \\
\hline UNAM & $463(38)$ & $104(35)$ & $359(40)$ & \multirow[t]{3}{*}{0.214} \\
\hline Other public university & $660(55)$ & $166(56)$ & $494(54)$ & \\
\hline Other private university & $84(7)$ & $26(9)$ & $58(6)$ & \\
\hline \multicolumn{5}{|l|}{ Year completed medical training } \\
\hline 1990-2002 & $413(34)$ & $97(33)$ & $316(35)$ & \multirow[t]{3}{*}{0.519} \\
\hline $1980-9$ & $485(40)$ & 116 (39) & $369(41)$ & \\
\hline Before 1980 & $308(26)$ & $83(28)$ & $225(25)$ & \\
\hline \multicolumn{5}{|l|}{ Type of practice } \\
\hline Public & $395(33)$ & $59(20)$ & $336(37)$ & \multirow[t]{4}{*}{0.000} \\
\hline Private & $487(40)$ & $117(40)$ & $370(41)$ & \\
\hline Both public and private & $325(27)$ & $120(41)$ & $205(23)$ & \\
\hline \multicolumn{4}{|l|}{2 weeks } & \\
\hline Yes & $1037(86)$ & $264(89)$ & $773(85)$ & \multirow{2}{*}{0.068} \\
\hline No & $170(14)$ & 32 (11) & $138(15)$ & \\
\hline
\end{tabular}

analysis it was deemed appropriate to group the two physician types under the category of "non-specialists."

\section{RESULTS}

Of the 1586 eligible physicians, 1206 providers working in a total of 288 medical facilities agreed to participate, resulting in a response rate of $76 \%$. Private sector physicians had a higher non-response rate than those working in the public sector $(28 \% v 21 \%)$. Approximately one third of respondents corresponded to each of the three regions of the country $(33 \%$ north, $36 \%$ central, and $31 \%$ south).

Table 2 shows key characteristics of the study population by provider type. Approximately half of the respondents were GPs (54\%), followed by Ob-Gyns (25\%) and family doctors $(21 \%)$. The majority were from the central region where the capital, Mexico City, is located, and significantly more ObGyns were from the north. Respondents' age ranged from between 24 and 60, with an average age of 42. Most were male, married, or had a 2 week salary of between 3500 and 9000 Mexican pesos (roughly \$US865). Roughly 86\% self identified as Catholic-fairly consistent with the national average-although $41 \%$ reported to never or almost never attend religious services. The majority of physicians graduated from public universities.

Approximately $40 \%$ of respondents reported to work exclusively in the private sector, and Ob-Gyns were significantly less likely than GPs to work only in public institutions $(20 \% \vee 37 \%)$. The majority of providers had ordered or performed a Pap test in the 2 weeks before the survey.

\section{Cervical cancer screening: knowledge and practices}

Most respondents had either been informed about or had read the official Mexican norms for cervical cancer (table 3 ). Despite this, there was discrepancy regarding the recommended periodicity for obtaining routine Pap tests. Importantly, current Mexican norms do not specify at what point or age women should initiate Pap testing. While $77 \%$ of all respondents said that women should begin having Pap tests after first sexual intercourse regardless of age, 10\% of GPs said that women should initiate Pap tests after the birth of their first child. With regard to the appropriate interval for Pap testing, $73 \%$ of both Ob-Gyns and GPs recommended annual screening given a previous normal Pap test. However, 
Table 3 Knowledge about cervical cancer screening protocols and HPV, by type of provider $(n=1206)^{*}$

\begin{tabular}{|c|c|c|c|c|}
\hline \multirow[b]{2}{*}{ Variable } & \multirow[b]{2}{*}{ Total } & \multicolumn{3}{|c|}{ Provider type } \\
\hline & & $\begin{array}{l}\text { Ob-Gyn } \\
\text { No (\%) }\end{array}$ & $\begin{array}{l}\text { GP } \\
\text { No (\%) }\end{array}$ & p Value \\
\hline \multicolumn{5}{|l|}{ Read or been informed about official norms on cervical cancer } \\
\hline Yes & $996(83)$ & $251(85)$ & $745(82)$ & \multirow{2}{*}{0.216} \\
\hline No & 209 (17) & $44(15)$ & $165(18)$ & \\
\hline \multicolumn{5}{|l|}{ When recommends for women to have first Pap test } \\
\hline In late adolescence (16-19 years) or after first sexual intercourse & $119(10)$ & $32(11)$ & $87(10)$ & \multirow[t]{4}{*}{0.029} \\
\hline After first sexual intercourse regardless of age & $932(77)$ & $240(81)$ & $692(76)$ & \\
\hline After birth of first child & $104(9)$ & $15(5)$ & $89(10)$ & \\
\hline Other & $51(6)$ & $8(3)$ & $43(5)$ & \\
\hline \multicolumn{5}{|l|}{ Should women continue to get routine Pap tests after menopause } \\
\hline Yes & $1124(93)$ & $274(93)$ & $850(93)$ & \multirow{2}{*}{0.789} \\
\hline No & $81(7)$ & $21(7)$ & 60 (7) & \\
\hline \multicolumn{5}{|l|}{ Time that woman should wait for next Pap if previous test normal } \\
\hline 6 months & $193(16)$ & $53(18)$ & $140(15)$ & \multirow[t]{4}{*}{0.098} \\
\hline 1 year & $880(73)$ & $216(73)$ & 664 (73) & \\
\hline 3 years & $95(8)$ & $23(8)$ & $72(8)$ & \\
\hline Other & 37 (3) & $3(1)$ & $34(4)$ & \\
\hline \multicolumn{5}{|l|}{ Principal cause of cervical cancer } \\
\hline Human papillomavirus (HPV) & $968(80)$ & $253(86)$ & $715(79)$ & \multirow[t]{3}{*}{0.000} \\
\hline Family history of cervical cancer & $175(15)$ & $21(7)$ & $154(17)$ & \\
\hline Other (herpes virus, poor genital hygiene, OC pills, smoking) & $64(5)$ & $22(7)$ & $42(5)$ & \\
\hline \multicolumn{5}{|l|}{ Knew about HPV cervical cancer link before reading paragraph* } \\
\hline Yes & $1161(96)$ & $288(97)$ & $873(96)$ & \multirow[t]{2}{*}{0.297} \\
\hline No & $46(4)$ & $8(3)$ & $38(4)$ & \\
\hline \multicolumn{5}{|l|}{ Had heard about oncogenic types of HPV before paragraph } \\
\hline Yes & $1013(84)$ & $283(96)$ & $730(80)$ & \multirow[t]{2}{*}{0.000} \\
\hline No & $192(16)$ & $12(4)$ & $180(20)$ & \\
\hline \multicolumn{5}{|l|}{ HPV types $16,18,31,38$, and 45 also cause genital warts } \\
\hline Yes & $739(61)$ & $185(63)$ & $554(61)$ & \multirow[t]{3}{*}{0.000} \\
\hline No & $225(19)$ & $83(28)$ & $142(16)$ & \\
\hline Don't know & $243(20)$ & $28(10)$ & $215(24)$ & \\
\hline
\end{tabular}

$18 \%$ of Ob-Gyns incorrectly said that Pap tests should be repeated every 6 months regardless of previous results.

With regard to physicians' counselling practices during routine Pap tests, approximately $80 \%$ reported to always counsel women on the purpose of the Pap test, the meaning of test results, and the benefit of having a Pap (data not shown). Significantly more Ob-Gyns (58\%) than GPs (45\%) said that they counselled women about the relation between smoking and cervical cancer $(p<.001)$. Nearly $60 \%$ of all respondents reported to regularly counsel women about the relation between unsafe sex and cervical cancer.

Respondents were also asked about knowledge and practices for the management of mild or moderate dysplasia, or CIN I and II as classified under the cervical intraepithelial neoplasia system (table 4). National guidelines consider electrosurgery, laser therapy, and cryotherapy as preferred management options for CIN I, II, or III, and hysterectomy is not recommended. Among GPs, 18\% had performed a hysterectomy in the past year to treat CIN I or II, and between $11 \%$ and $15 \%$ had performed laser therapy, electrosurgery, or cryotherapy. Ob-Gyns were significantly more likely than GPs to both identify hysterectomy as a management option for low grade lesions (37\%) and to have performed one in the past year for this indication (43\%). Thirty per cent of physicians working in the private sector had performed a hysterectomy in the past year, compared to $13 \%$ of public sector physicians and $27 \%$ of providers working in both sectors $(\mathrm{p}<0.05)$.

Regarding physicians' strategies for keeping updated on clinical advances in cervical cancer prevention and treatment (data not shown), the most frequently cited source was medical journals $(83 \%)$, followed by continuing medical

Table 4 Knowledge and practices regarding management of $\mathrm{CIN}$ I and $\mathrm{CIN}$ II* $(n=1206) \dagger$

\begin{tabular}{|c|c|c|c|c|c|}
\hline & \multicolumn{2}{|c|}{ Provider type } & \multicolumn{3}{|l|}{ Sector } \\
\hline & $\begin{array}{l}\text { Ob-Gyn } \\
\text { No (\%) }\end{array}$ & $\begin{array}{l}\text { GP } \\
\text { No (\%) }\end{array}$ & $\begin{array}{l}\text { Public } \\
\text { No (\%) }\end{array}$ & $\begin{array}{l}\text { Private } \\
\text { No }(\%)\end{array}$ & $\begin{array}{l}\text { Both } \\
\text { No (\%) }\end{array}$ \\
\hline \multicolumn{6}{|c|}{ Is an option for CIN I or CIN II } \\
\hline Hysterectomy & $108(37)$ & $227(25)$ & $82(21)$ & $166(34)$ & $88(27)$ \\
\hline Electrosurgery & $217(73)$ & $360(40)$ & $159(40)$ & $230(47)$ & $188(58)$ \\
\hline Laser therapy & $163(55)$ & $292(32)$ & $118(30)$ & $177(36)$ & $160(49)$ \\
\hline Cryotherapy & $205(70)$ & $471(52)$ & $192(49)$ & $286(59)$ & $197(61)$ \\
\hline \multicolumn{6}{|c|}{ Has performed for CIN I or CIN II } \\
\hline Hysterectomy & $126(43)$ & $161(18)$ & $53(13)$ & $148(30)$ & $86(27)$ \\
\hline Electrosurgery & $154(52)$ & $120(13)$ & $50(13)$ & $126(26)$ & $98(30)$ \\
\hline Laser therapy & $68(23)$ & 98 (11) & $30(8)$ & $79(16)$ & $57(18)$ \\
\hline Cryotherapy & $151(51)$ & $139(15)$ & $53(14)$ & $132(27)$ & 105 (32) \\
\hline
\end{tabular}


training $(74 \%)$, conferences $(73 \%)$, the internet $(54 \%)$, and colleagues (34\%). Responses for this question did not differ significantly between Ob-Gyns and GPs.

\section{HPV knowledge and opinions on patient counselling}

As table 3 shows, $86 \%$ of Ob-Gyns and $79 \%$ of GPs identified HPV as the principal cause of cervical cancer. GPs were more likely than Ob-Gyns to say that a family history of cervical cancer was the main causal factor. In response to this multiple choice question, a small number of physicians mentioned other factors including the herpes virus, poor genital hygiene, oral contraceptive pills, and smoking. Following a brief paragraph explaining the relation between HPV and cervical cancer, nearly all respondents reported to have previously heard about the association. (The paragraph read as follows: HPV is sexually transmitted and is the most common cause of cervical cancer throughout the world. Not all strains of HPV are oncogenic; the most high risk strains are types 16, 18, 31, 33, and 45 . In some cases the infection disappears on its own and in others it progresses to cancer.) Ob-Gyns were significantly more likely to have heard about the most common oncogenic strains of HPV (96\% $\vee 80 \%$; $\mathrm{p}<.001$ ). However, roughly $62 \%$ of both Ob-Gyns and GPs incorrectly identified HPV types 16, 18, 31, 38, and 45 as also causing genital warts. GPs were more than twice as likely as Ob-Gyns to report not knowing whether these strains did or did not cause warts.

Nearly all respondents (99\%) said that women in the general public should be informed that HPV is the principal cause of cervical cancer (data not shown). With respect to appropriate settings for or means of educating women on this topic, comparable proportions of Ob-Gyns and GPs (80-90\%) said during routine Pap tests, at family planning clinics, in universities, through public education campaigns, and in high schools.

Table 5 shows physicians' opinions about potential consequences of informing women that HPV is the main cause of cervical cancer, by type of provider and region. The question was presented as a list of statements to which respondents could answer "strongly agree," "somewhat agree," "somewhat disagree," and "strongly disagree." Data were analysed using both these responses and, as presented here, collapsing responses into agree/disagree. Thirty seven per cent of Ob-Gyns agreed that this information would cause unnecessary anxiety among women. A roughly equal proportion of Ob-Gyns and GPs (37\% and 35\% respectively) also thought that women would not be able to understand this information. Physicians in the north were more than twice as likely as those in the central region to believe that the association between HPV and cervical cancer is not sufficiently established and that providers would not know how to counsel women on this topic $(p<0.05)$. With the exception of GPs, the majority of respondents also thought that this information could cause conflict in intimate partner relationships. Relatively few respondents thought that knowing that an STI causes cervical cancer would dissuade women from having Pap tests.

\section{DISCUSSION}

\section{Study limitations}

Owing to lack of databases necessary to create the sampling frame for randomising individual physicians, this study was based on a probability sample at the health facility level in urban Mexico. Although the facilities represented a random sample, the providers surveyed within each facility comprised a convenience sample. One potential problem with this sampling strategy is that those providers who participated may not be representative of all providers who worked in these facilities. This would be of particular concern if the providers who were selected had characteristics that made them different from other providers with respect to their level of knowledge or attitudes on HPV and cervical cancer. In particular, since the larger survey also included questions on abortion, it is possible that the providers who agreed to participate were more likely to hold certain views on abortion that would affect their views on HPV and cervical cancer. In fact, survey findings suggest considerable diversity with respect to physicians' views on abortion. As reported elsewhere, ${ }^{14} 55 \%$ of the sample said they would be willing to perform a legal abortion in a public institution, suggesting that the sample was not overwhelmingly pro-choice or antichoice despite being largely Catholic. Indeed, while $86 \%$ self identified as Catholic, $42 \%$ reported to rarely or never attend religious services.

A second limitation is that the exclusion of rural areas from the sampling frame means that study findings are not generalisable to providers in these areas. Providers practising in rural Mexico were considered less appropriate participants for our survey for reasons explained earlier. However, future studies on cervical cancer and HPV should undoubtedly focus on this population, considering the poor quality of screening, treatment, and counselling services in rural Mexico.

A third potential problem is that the questionnaire included an informational paragraph on HPV in order to provide respondents with basic facts with which to answer the opinion questions on patient education. It is possible that respondents changed their answers to some of the HPV questions after reading the paragraph, although the fact that the survey was anonymous and confidential, and as many as $20 \%$ of GPs admitted to not having heard about high risk HPV strains after reading the paragraph, suggests that many did not. Perhaps a better measure of physicians' knowledge about HPV is the question on whether high risk strains cause genital warts-a topic not covered in the paragraph and one that $61 \%$ of all respondents answered incorrectly.

Table 5 Providers agreeing with the following possible consequences of informing women about the relation between HPV and cervical cancer $(n=1206)$

\begin{tabular}{|c|c|c|c|c|c|}
\hline \multirow[b]{2}{*}{ Opinion } & \multicolumn{2}{|c|}{ Provider type } & \multicolumn{3}{|l|}{ Region } \\
\hline & $\begin{array}{l}\text { Ob-Gyn } \\
\text { No }(\%)\end{array}$ & $\begin{array}{l}\text { GP } \\
\text { No (\%) }\end{array}$ & $\begin{array}{l}\text { Central } \\
\text { No }(\%)\end{array}$ & $\begin{array}{l}\text { North } \\
\text { No (\%) }\end{array}$ & $\begin{array}{l}\text { South } \\
\text { No (\%) }\end{array}$ \\
\hline This information would cause unnecessary anxiety for women & 109 (37) & $255(28)^{*}$ & $227(29)$ & $91(42)$ & $46(23)^{*}$ \\
\hline Women would not understand this information & 109 (37) & $320(35)$ & $244(31)$ & $108(50)$ & $77(39)^{*}$ \\
\hline $\begin{array}{l}\text { The association between HPV and cervical cancer is not scientifically } \\
\text { documented }\end{array}$ & $71(24)$ & $178(20)$ & 129 (16) & $77(36)$ & $43(21)^{*}$ \\
\hline Providers would not know how to counsel women on this topic & $60(20)$ & $162(18)$ & $116(15)$ & $69(32)$ & $37(18)^{*}$ \\
\hline Women would be less likely to have Pap tests & $68(23)$ & $234(26)$ & 176 (22) & $82(38)$ & $44(22)^{*}$ \\
\hline This information could create problems in relationships & $191(65)$ & 530 (58) & $466(59)$ & $128(59)$ & $127(63)$ \\
\hline
\end{tabular}


Provider knowledge about cervical cancer and HPV Providers surveyed generally had accurate knowledge about Pap test norms and the appropriate periodicity with which women should be screened. Still, it is troubling that $10 \%$ of GPs believed that women should initiate Pap tests after giving birth to their first child. In addition to the already low screening coverage in Mexico, well over 50\% of Mexican women will initiate sexual activity several years before their first child if they have children, ${ }^{15}$ thus exposing them to HPV infection that can progress to various degrees of dysplasia over time. It is important to note that even the updated 1998 Mexican norms, which provide more explicit guidelines on screening and treatment protocols and public education, do not specify when women should begin having Pap tests. The recently revised American Cancer Society guidelines recommend that women initiate Pap tests roughly 3 years after first intercourse but no later than age $21 .{ }^{16}$ It is essential that the Mexican Ministry of Health determine and include protocols for Pap test initiation in clinical norms.

The interval that women should wait to get Pap tests continues to be an area of discrepancy in Mexico, and findings suggest a gap between national guidelines and practice. Although the majority of physicians in this study correctly recommended annual Pap testing given a previous normal result, $18 \%$ of Ob-Gyns said that women should be tested again in 6 months. This latter recommendation has been documented in a previous study with Mexican providers. ${ }^{13}$ It is possible that doctors tell patients to come in earlier than clinically indicated, assuming that they will return later if at all. However, studies have clearly established that annual screening yields minimal gains compared to screening every 3 years, in terms of reducing cumulative cancer rates. ${ }^{17}$ Mexican norms recommend that women be screened every 3 years given two normal Pap tests of no more than a year apart and in the absence of HPV infection. The 2001-6 Program of Action on Cervical Cancer also states that, given epidemiological evidence, annual or semi-annual screening is unnecessary. ${ }^{18}$ Semi-annual screening of a small portion of the population (likely the most low risk), while many women are never screened, is evidence of poor distribution of resources in Mexico's cervical cancer prevention programme.

Findings regarding physicians' knowledge and management of mild or moderate dysplasia suggest misuse of hysterectomy. Again, physicians might justify aggressive treatment given the tendency for women to not seek necessary follow up care. Many factors influence the decision to perform a hysterectomy, including the woman's age, additional risk factors, desire to discontinue childbearing, and the physician's own financial incentives. Regardless, given the problems associated with the "epidemic" proportion of hysterectomies in Latin America, appropriate dysplasia management is a priority area for provider education.

With respect to cervical cancer aetiology and causes, physicians in this study appear to have better basic knowledge about HPV compared with those surveyed in $1998 .^{13}$ Anecdotal evidence also indicates a growing awareness in the medical community about HPV. Nevertheless, both GPs and Ob-Gyns showed poor detailed knowledge about HPV, thus pointing to another area where physician education is needed.

\section{Physicians' opinions on patient education about HPV} Mexican providers in our study strongly supported HPV education for women, in a variety of settings ranging from routine Pap examinations to universities and high schools. Researchers have suggested that this information would stigmatise cervical cancer and thus reduce participation in cancer screening. ${ }^{19}{ }^{20}$ Our study suggests the opposite- that is, few Mexican doctors believed that knowledge about the causal relation between an STI and cervical cancer would discourage women from having Pap tests.

Education about HPV will inevitably become more common, and since the inception of this study, there have been an increasing number of HPV public service announcements in Mexico. Further research in the area of patient counselling is needed, however, especially in light of current research into new HPV related technologies; though years away from marketing, research on both HPV tests and vaccines will have important implications for middle income countries like Mexico, and at least one study has assessed acceptability for an HPV trial vaccine in the state of Morelos. ${ }^{8}$ The key will be to frame appropriate and effective messages that minimise confusion, pre-empt unnecessary anxiety, and take into account men's role in both prevention and risk. A study in Great Britain showed that information about HPV tended to cause confusion among women who did not previously know about its link with cervical cancer. ${ }^{21}$ In Mexico, the fact that roughly $66 \%$ of women diagnosed with cervical cancer in 2000 were illiterate or had only incomplete primary school education ${ }^{17}$ highlights the need for clarity and consistency in educational messages.

In addition, that most physicians believed information about HPV would cause problems in partner relationships is important, as it points to the increasingly expanded counselling role of healthcare professionals. Above all, and especially if combination HPV/Pap testing is to be introduced in Mexico in the future, providers need to be armed with accurate information to share with women and their partners, as well as an awareness of and sensitivity to the implications this information carries. For example, when giving a positive HPV diagnosis to a patient, providers might explain that such a diagnosis should not be taken as an indication of the woman's or her partner's sexual behaviour, as it is impossible to know when HPV was acquired or from whom.

\section{CONCLUSIONS}

This is the first study to evaluate provider knowledge and attitudes about cervical cancer and HPV on a national level in Mexico, a country with an unacceptably high cervical cancer mortality rate. Findings suggest the need for educational interventions with Mexican physicians, especially through increasing access to up to date information in medical journals, the internet, and implementing continuing education programmes. In fact, the present study was part of a package of provider studies in Mexico. Based on findings from a survey carried out with public sector providers in Mexico City, educational physician workshops on HPV and cervical cancer are being planned. Secondly, in addition to testing counselling messages aimed at women and the public,

\section{Key messages}

- Both obstetricians-gynaecologists and general practitioners in Mexico would benefit from further education about human papillomavirus (HPV) and cervical cancer, particularly screening and management protocols

- Mexican physicians generally support patient education about HPV and do not think that such information will discourage women from having Pap tests

- Informing women that HPV is a main cause of cervical cancer can cause confusion, anxiety, and conflict in partner relationships; therefore the topic must be handled with clarity and sensitivity in the clinical setting 
it will be necessary to do evaluation research to determine the effects of current HPV education campaigns.

\section{ACKNOWLEDGEMENTS}

The authors would like to thank Investigación de Mercado y Asesoría for their assistance in sampling and data collection. We also thank Sarah Landis, Ana Langer, Patricio Sanhueza, Felipe Santana, Raffaela Schiavon, and Juan Zinser for review of the questionnaire and manuscript. This study was supported by the William and Flora Hewlett Foundation.

\section{CONTRIBUTORS}

TA contributed to the development of the questionnaire, conducted data analysis, and wrote the manuscript; DB contributed to the development of the questionnaire, and to manuscript revisions; SG assisted in revising the study protocol, questionnaire, and manuscript; DL drafted the study protocol and oversaw fieldwork.

\section{Authors' affiliations}

T Aldrich, D Becker, S G García, D Lara, Population Council, Regional Office for Latin America and the Caribbean, Mexico City, Mexico

\section{REFERENCES}

1 World Health Organization, www.who.int/en/ (accessed 8 July 2003).

2 Blumenthal PD, Ringers P, Mclnthosh N, et al. Innovative approaches to cervical cancer prevention. Medscape Women's Health 2001;6:1.

3 Flores Y, Keerti S, Lazcano-Ponce E, et al. Design and methods of the evaluation of an HPV-based cervical cancer screening strategy in México: The Morelos HPV Study. Salud Publ Mex 2002;44:335-44.

4 Lazcano-Ponce E, Moss S, Alonso de Ruiz P, et al. Cervical cancer screening in developing countries: why is it ineffective? Arch Med Res 1999;30:240-50.

5 Bosch FX, Lorincz A, Muñoz N, et al. The causal relation between human papillomavirus and cervical cancer. J Clin Pathol 2002;55:244-65.
6 American Social Health Association, www.ashastd.org/hpvccrc/index.html (accessed 7 July 2003).

7 National Cervical Cancer Education Campaign,

www.cervicalcancercampaign.org/home.htm (accessed 7 July 2003).

8 Lazcano-Ponce EC, Rivera L, Arillo-Santillan E, et al. Acceptability of a human papillomaviurs (HPV) trial vaccine among mothers of adolescents in Cuernavaca, México. Arch Med Res 2001;32:243-7.

9 About HPV Infections. National Cancer Institute, Division of Cancer Prevention, www3.cancer.gov/prevention/alts/abouthpv.html (accessed 14 July 2003).

10 Sellors JW, Karwalaitys TL, Kaczorowski J, et al. Incidence, clearance and predictors of human papillomavirus infection in women. J Can Med Assoc 2003;168:421-5.

11 World Health Organization. The World Health Report. Life in the 21st century. A vision for all. Geneva: WHO, 1998.

12 Manhart LE, Koutsky LA. Do condoms prevent genital HPV infection, external genital warts, or cervical neoplasia? A meta-analysis. Sex Transm Dis 2002;29:725-35.

13 Arillo-Santillan E, Lazcano-Ponce E, Peris $M$, et al. Knowledge of health professionals about the prevention of cancer of the cervix: alternatives to medical education. Salud Pub Mex 2000;42:34-42.

14 Garcia SG, Lara D, Goldman L. Mexican physicians' knowledge, attitudes and practices regarding abortion: findings from a national survey. Gaceta Médica 2003;139(Suppl):S91-S102.

15 National Population Council of Mexico (CONAPO). Estimates based on the National Health Survey, 2000, and the National Family Planning Survey 1995.

16 CA Cancer J Clin 2002;52:375-6.

17 International Agency for Research on Cancer, 1986.

18 Secretary of Health. Program of action: cervical cancer, 1st ed. 2002.

19 Braun V, Gavey N. Exploring the possibility of sexual-behavioral primary prevention interventions for cervical cancer. Aust N Z J Pub Hlth 1998;22(Suppl):353-9.

20 Fernández-Esquier ME, Ross MW, Torres I. The importance of psychological factors in the prevention of HPV infection and cervical cancer. Int J STD AIDS 2000;11:701-13.

21 McCaffery KJ, Forrest S, Waller J, et al. Attitudes towards HPV testing: a qualitative study of beliefs among Indian, Pakistani, African Caribbean and white British women in the UK. Br J Cancer 2003;88:42-6. 